05

\title{
Автоволновое описание пластичности материалов с нестабильной фазовой структурой на макромасштабном уровне
}

\author{
() В.И. Данилов, Л.Б. Зуев, В.В. Горбатенко, Л.В. Данилова, Д.В. Орлова \\ Институт фризики прочности и материаловедения СО РАН, \\ 634055 Томск, Россия \\ e-mail: dvi@ispms.ru
}

Поступило в Редакцию 29 января 2020 г.

В окончательной редакции 9 июня 2020 г.

Принято к публикации 22 июня 2020 г.

Рассмотрены закономерности пластического течения в материалах с деформационно-индуцированными фазовыми превращениями на примере никелида титана и trip-стали. Для экспериментального анализа процессов пластической деформации использована методика цифровой корреляции спекл-изображений, позволяющая количественно описывать поведение фронтов пластичности, связанных с протеканием фазовых превращений в исследуемых материалах. Рассмотрены механизмы формирования фронтов Людерса и фронтов Портевена-Ле Шателье на разных стадиях пластического течения.

Ключевые слова: деформация, пластичность, автоволны, прерывистая текучесть, фазовые превращения, дефекты.

DOI: $10.21883 / J T F .2021 .02 .50361 .35-20$

\section{Введение}

Исследование термоупругих мартенситных превращений в высокопрочных материалах является важной задачей современного материаловедения, так как они являются механизмом реализации технологически важных явлений: эффекта памяти формы, сверхэластичности, повышенной пластичности в сочетании с высокой прочностью и высокой вязкостью разрушения. В настоящее время внимание привлекают проявления деформационно-индуцированных фазовых превращений на макроскопическом уровне, которые не только в монокристаллах, но и в поликристаллических объектах могут развиваться путем формирования и распространения локализованных фронтов фазового превращения [1-5].

Как установлено [6], пластическая деформация развивается локализовано на всех стадиях нагружения от упругопластического перехода до разрушения и на всех пространственных и временных масштабах, так что в качестве характеристик пластической деформации можно использовать форму и пространственно-временное распределение очагов локализованной пластичности по объему. В рамках этой концепции деформируемый объект представляет собой универсальный генератор автоволновых мод локализованной пластичности. Установлено правило соответствия, согласно которому тип автоволновой моды определяется законом упрочнения, действующим на данной стадии деформационной кривой [6]. На участках с нулевым упрочнением наблюдаются автоволны переключения в виде движения одиночных очагов локализованной деформации. На стадиях с постоянным коэффициентом упрочнения формируются фазовые автоволны в виде движущихся пространственнопериодических очагов локализованной деформации. На стадиях параболического упрочнения возникают неподвижные системы пространственно-периодических очагов, называемые стационарными диссипативными структурами. Наконец, на стадиях предразрушения происходит коллапс автоволн, т.е. стягивание очагов локализованной деформации в шейку вязкого разрушения. Правило соответствия сформулировано на базе экспериментов, выполненных в основном на поликристаллических объектах с дислокационным механизмом реализации пластического течения [6]. Стадии кривых упрочнения в таких материалах выявляются нечетко, а их границы размыты.

Исследование фронтов деформационно-индуцированных фазовых превращений открывает новые возможности для развития автоволновой концепции пластической деформации. Так, в сверхэластичных материалах можно изучать зарождение и кинетику фронтов прямого и обратного мартенситного превращения на одном образце в постоянных температурных условиях, как автоволн переключения. В trip-сталях происходит преобразование фронтов полос Людерса (LB) во фронты полос Портевена-Ле Шателье (PLC). Этим вопросам и посвящена настоящая работа.

\section{1. Материалы и экспериментальные процедуры}

Для исследований кинетики деформационных фронтов в сверхэластичном материале был использован никелид титана (NiTi) состава 55.96 wt.\% Ni-44.04 wt.\% Тi. Из пластин толщиной $2 \mathrm{~mm}$ в состоянии поставки были электроискровым способом вырезаны плоские образцы типа „собачья косточка“ с размерами рабочей части 
Режимы термомеханической обработки образцов trip-стали

\begin{tabular}{l|c|c}
\hline \multirow{1}{*}{ Образцы } & \multicolumn{2}{|c}{ Состояние } \\
\cline { 2 - 3 } & 1 & 2 \\
\hline Отжиг, $T=875 \mathrm{~K}, \tau=1 \mathrm{~h}$, & + & - \\
охлаждение с печью & & \\
$\begin{array}{l}\text { Аустенизация (закалка), } \\
T=1400 \mathrm{~K}, \tau=1 \mathrm{~h},\end{array}$ & - & + \\
$\begin{array}{l}\text { охлаждение в воде } \\
\text { Многопроходная „теплая“ }\end{array}$ & - & + \\
прокатка, $T=620 \mathrm{~K}$ \\
$\begin{array}{l}\text { Обжатие при прокатке, \% } \\
\text { Содержание аустенита, \% }\end{array}$ & - & 40 \\
\end{tabular}

$40 \times 6 \mathrm{~mm}$. Подготовленные образцы подвергались закалке от $1073 \mathrm{~K}$ в воду. Нагрев осуществлялся в гелиевой атмосфере. После термообработки исследуемый материал находился в аустенитном состоянии (структура В2) и имел следующие характерные температуры: $M_{s}=246 \mathrm{~K}, M_{f}=213 \mathrm{~K}, A_{s}=243 \mathrm{~K}, A_{f}=259 \mathrm{~K}$. Это позволяло наблюдать при $300 \mathrm{~K}$ как прямое $B 2 \rightarrow B 19^{\prime}$, так и обратное $B 19^{\prime} \rightarrow B 2$ мартенситные превращения (эффект сверхэластичности [7]).

Поведения фронтов деформационно-индуцированного фазового превращения в материале с прерывистой текучестью исследовались на образцах аустенитномартенситной trip-стали состава, [\% wt]: $0.20-0.25 \mathrm{C}$; $14.5-16.0 \mathrm{Cr} ; 4.8-5.8 \mathrm{Ni} ; 2.7-3.2 \mathrm{Mo} ; \mathrm{Mn} \leq 1.0 ; \mathrm{Si} \leq 0.6$; $0.03-0.07 \mathrm{~N} ; \mathrm{S} \leq 0.01 ; \mathrm{P} \leq 0.015 ; \mathrm{Fe}-$ основа. Предварительно пластины стали толщиной $1 \mathrm{~mm}$ в состоянии поставки подвергались термомеханической обработке по двум разным режимам (см. таблицу). Величиной обжатия при прокатке регулировались количество и степень наклепа метастабильного аустенита. Для каждого состояния были подготовлены по пять образцов таких же размеров, как и образцы никелида титана.

Образцы испытывались на одноосное растяжение при $300 \mathrm{~K}$ на универсальной машине Walter Bay AG (модификация LFM 125). Одновременно методом корреляции цифровых изображений [8] регистрировалось поле локальных перемещений на поверхности образца. Для этого образец освещался когерентным светом полупроводникового лазера с длиной волны $635 \mathrm{~nm} \mathrm{и}$ мощностью $15 \mathrm{~mW}$. Полученные при таком освещении изображения деформируемого образца с наложенными на них спекл-картинами регистрировались цифровой видеокамерой Point Grey FL3-GE-50S5M-C с частотой $10 \mathrm{~s}^{-1}$, оцифровывались и запоминались. Компьютерная обработка изображений позволяла получить поля перемещений точек поверхности образца $\mathbf{r}(x, y)$, а затем пространственно-временные распределения локальных компонент тензора дисторсии для плоского случая.

В таком представлении пространственно-временные положения очагов, например локальных удлинений $\varepsilon_{x x}$, соответствуют положениям фронтов деформационно- индуцированных фазовых превращений, а эволюция картин локализации деформации отражает кинетику этих фронтов. Графически очаги деформации представляются в виде темных пятен на фоне изображения рабочей поверхности образца, контраст которых определяется амплитудой локализованной деформации. Треки движения этих пятен визуализируют фронты фазового превращения. Этот способ, известный как построение хронограмм $[9,10]$, позволяет измерять скорости движения фронтов и выявлять области их зарождения и аннигиляции.

\section{2. Результаты и обсуждение}

\section{1. Фронты деформационно-индуцированного фазового превращения в $\mathrm{NiTi}$}

Исследование деформационного превращения в никелиде титана производилось при $300 \mathrm{~K}$ в условиях одноосного нагружения при различных скоростях подвижного захвата испытательной машины $V_{\text {mach }}$. После окончания площадки текучести образец разгружался с такой же скоростью, как и при нагружении. На рис. 1 представлены примеры диаграмм деформации. Видно, что увеличение скорости $V_{\text {mach }}$ приводит к повышению уровня напряжений на площадке текучести при нагружении и уменьшению степени восстановления размеров образца при разгрузке. Формирование и движение фронтов как прямого, так и обратного деформационноиндуцированного превращения наблюдались при всех исследованных скоростях нагружения. Отличия состоят в количестве формирующихся фронтов и скоростях их движения. При увеличении $V_{\text {mach }}$ скорости фронтов фазового превращения возрастают, но при этом одновременно увеличивается их число. Анализ хронограмм, представленных на рис. 2-4, показывает, что при деформировании формируются полосы превращения, аналогичные LB в материалах с дислокационным механизмом деформации [9]. Границы полос фазового превращения

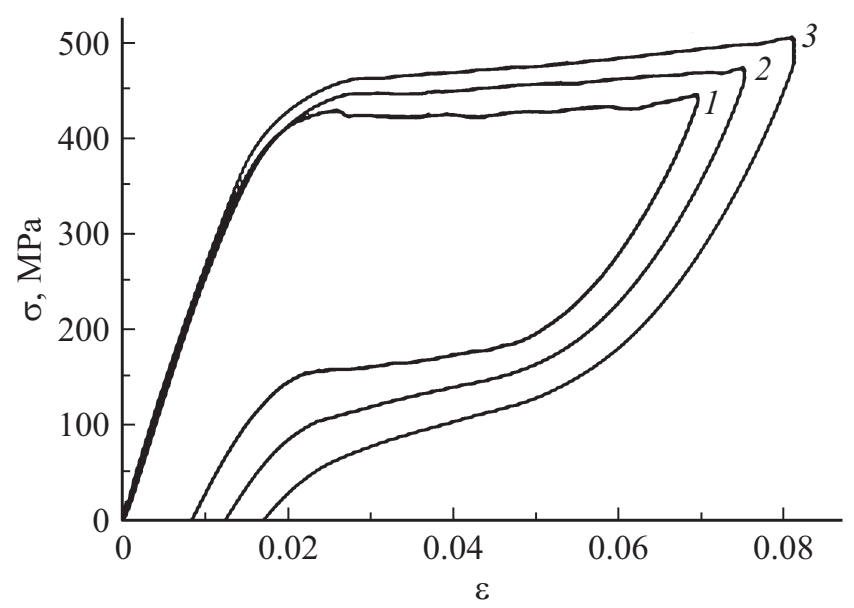

Рис. 1. Диаграммы нагружения никелида титана, $V_{\text {mach }}$ : $1-0.05,2-0.2,3-0.4 \mathrm{~mm} / \mathrm{min}$. 

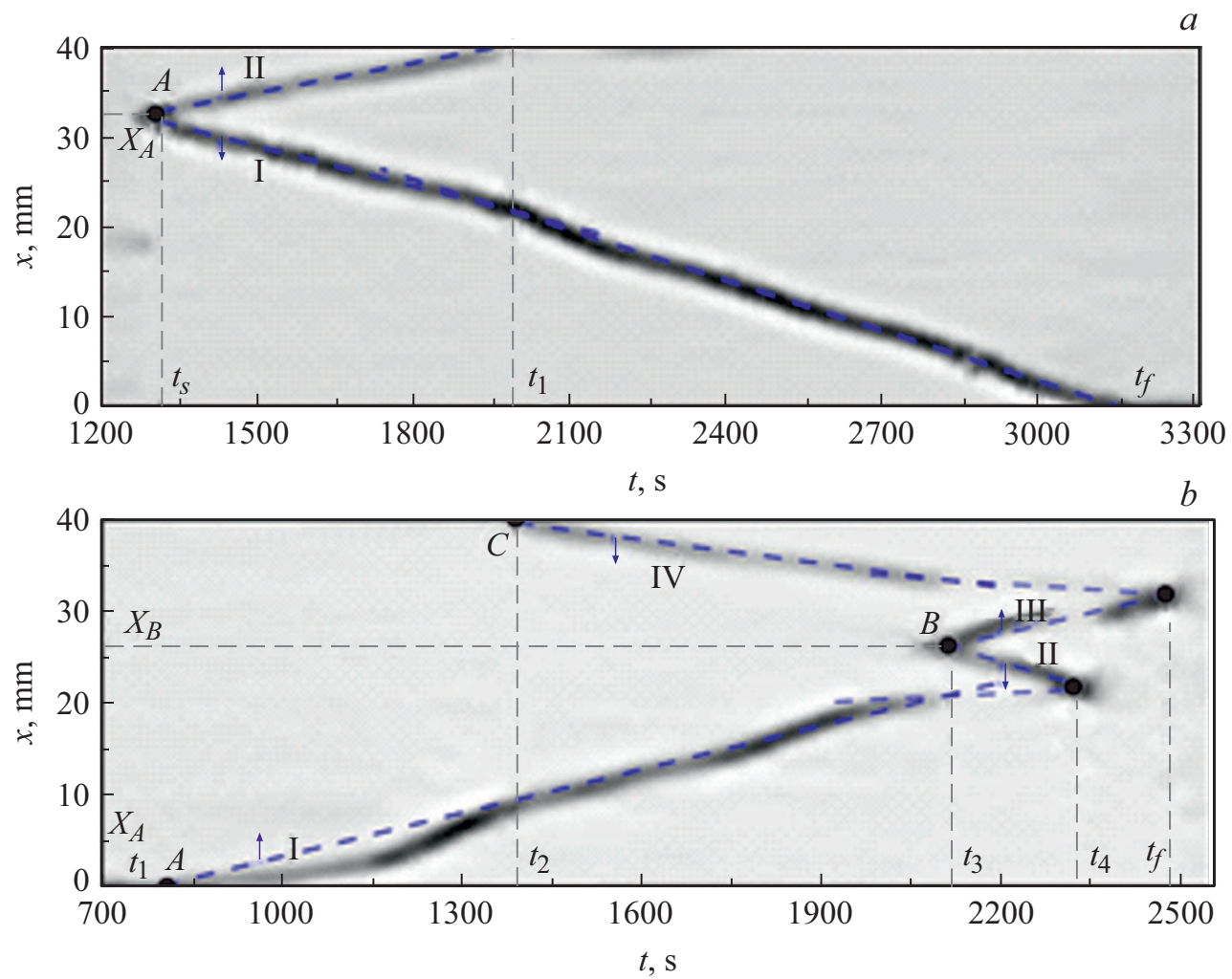

Рис. 2. Хронограммы фронтов прямого $(a)$ и обратного $(b)$ мартенситных превращений в никелиде титана; $V_{\text {mach }}=0.05 \mathrm{~mm} / \mathrm{min}$, стрелками указаны направления движения фронтов.
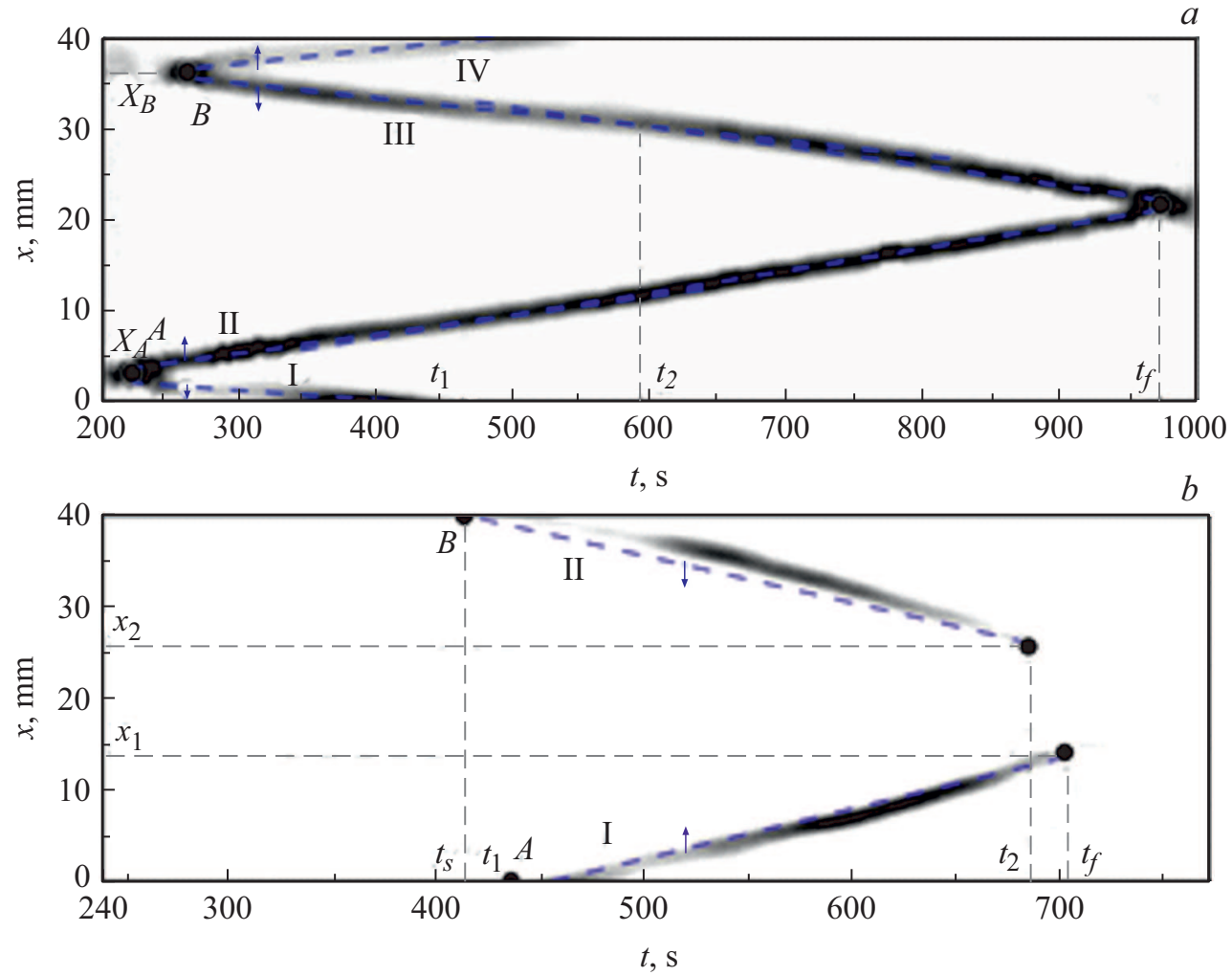

Рис. 3. Хронограммы фронтов прямого $(a)$ и обратного $(b)$ мартенситных превращений в никелиде титана; $V_{\text {mach }}=0.2 \mathrm{~mm} / \mathrm{min}$, стрелками указаны направления движения фронтов. 


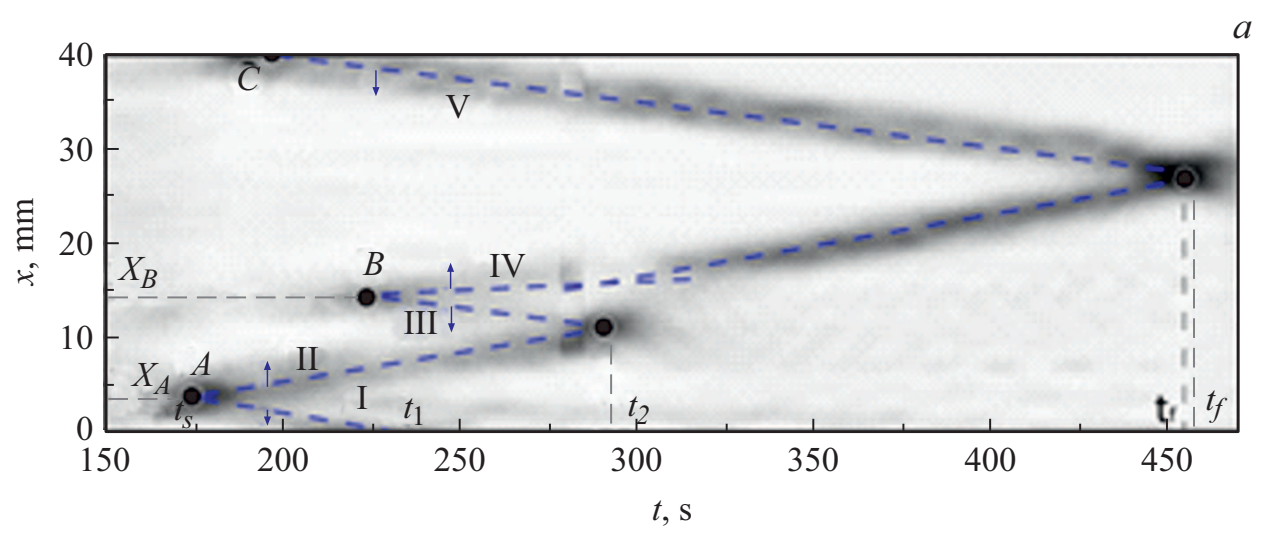

Рис. 4. Хронограмма фронтов прямого мартенситного превращения в никелиде титана; $V_{\text {mach }}=0.4 \mathrm{~mm} / \mathrm{min}$, стрелками указаны направления движения фронтов.

(фронты) отличаются от фронтов Людерса на порядок меньшей степенью локализации деформации, а также тем, что с ними связаны изменения не только локальных удлинений $\varepsilon_{x x}$, но и других компонент тензора дисторсии (сдвиги $\varepsilon_{x y}$ и повороты $\omega_{z}$ ).

Рассмотрим более подробно кинетику движения деформационного фронта в никелиде титана при прямом деформационно-индуцированном фазовом превращении. На хронограмме рис. 2, $a$ видно, что деформация при нагружении со скоростью $V_{\text {mach }}=0.05 \mathrm{~mm} / \mathrm{min}$ реализуется путем формирования одной полосы $A$ в зоне с координатой $x_{A}=33 \mathrm{~mm}$ в момент времени $t_{s}=1280 \mathrm{~s}$. Фронты этой полосы I и II движутся к границам рабочей части образца. Когда фронт II прекращает свое существование, уходя с рабочей части образца, наклон хронограммы к оси времени увеличивается, т. е. скорость фронта I возрастает от 0.14 до $0.21 \mathrm{~mm} / \mathrm{s}$. Превращение и площадка текучести заканчиваются в момент $t_{f}=3125 \mathrm{~s}$ при деформации $\varepsilon_{f}=0.065$.

Увеличение скорости нагружения до $0.2 \mathrm{~mm} / \mathrm{min}$ привело к зарождению двух полос превращения $A$ и $B$ (рис. 3,a). Координаты мест зарождения полос $x_{A}=3 \mathrm{~mm}$ и $x_{B}=36 \mathrm{~mm}$. После формирования каждая из полос имеет по два подвижных фронта (полоса $A-$ фронты I и II, полоса $B-$ фронты III и IV). Фронты I и IV движутся к захватам и уходят с рабочей части образца. Оставшаяся пара фронтов II и III продолжает движение и при встрече аннигилируют (момент времени $t_{f}=990 \mathrm{~s}$ на рис. 3,a), что соответствует окончанию фазового превращения и площадки текучести на кривой нагружения. Видно, что в моменты времени $t_{1}$ и $t_{2}$, когда фронты I и IV прекратили движение, скорости фронтов II и III возросли от 0.16 до $0.23 \mathrm{~mm} / \mathrm{s}$ и от 0.2 до $0.26 \mathrm{~mm} / \mathrm{s}$ соответственно.

При нагружении со скоростью $V_{\text {mach }}=0.4 \mathrm{~mm} / \mathrm{min}$ прямое превращение происходит за счет формирования полос $A, B$ и $C$ (рис. 4, $a$ ). Координаты зон зарождения полос $x_{A}=4 \mathrm{~mm}$ и $x_{B}=15 \mathrm{~mm}$, а полоса $C$ образовалась непосредственно на границе рабочей части образца у захвата и имеет один подвижный фрон V. Фронт I полосы $A$ исчез в момент времени $t_{1}$. Фронты II, III и IV, V попарно аннигилируют при встрече в моменты времени $t_{1}$ и $t_{f}$. Прекращение существования какоголибо из фронтов приводит к увеличению скоростей оставшихся. Момент аннигиляции фронтов IV и $\mathrm{V} t_{f}$ соответствует окончанию прямого мартенситного превращения.

Во всех трех случаях скорости движения фронтов превращения взаимосвязаны и обобщенная скорость фронтов фазового превращения (сумма модулей их скоростей)

$$
\tilde{V}_{f}=\sum_{i=1}^{N}\left|V_{f}^{(i)}\right|=\left(\frac{1}{\delta \varepsilon_{G}}+1\right) V_{m a c h}
$$

остается постоянной [10]. Здесь $\left|V_{f}^{(i)}\right|-$ модуль скорости движения $i$-го фронта, $N$ - число одновременно движущихся фронтов, $\delta \varepsilon_{g}-$ относительная деформация, накапливаемая на площадке текучести. Таким образом, обобщенная скорость фронтов должна возрастать с ростом скорости перемещения подвижного захвата испытательной машины в интервале $0.05 \leq V_{\text {mach }} \leq 0.8 \mathrm{~mm} / \mathrm{min}$. Зависимость $\tilde{V}_{f}$ от $V_{\text {mach }}$ представлена на рис. 5. Как показал анализ, она удовлетворительно (коэффициент корреляции 0.998) аппроксимируется степенной функцией вида

$$
\tilde{V}_{f}=K\left(V_{\text {mach }}\right)^{n}
$$

где $n=0.87$, а $K-$ константа. Подобная зависимость была получена ранее для обобщенных скоростей фронтов в малоуглеродистой стали, причем для этого случая также $n=0.87[9,10]$. Слабая нелинейность зависимости (2), возможно, обусловлена тем, что с ростом скорости $V_{\text {mach }}$ увеличивается деформация, накапливаемая на площадке текучести (рис. 1).

Важные данные о кинетике обратного мартенситного превращения были получены при разгрузке образцов. Хотя полного восстановления их размеров и формы в этом случае не происходит, и горизонтальная полка 
на диаграмме разгрузки отсутствует, наблюдалось движение фронтов обратного фазового превращения. Их зарождение детерминировано протеканием прямого превращения. Так, на хронограмме рис. $2, b$ можно видеть, что при $V_{\text {mach }}=0.05 \mathrm{~mm} / \mathrm{min}$ зарождение первой полосы обратного превращения происходит у неподвижного захвата, где завершилось прямое мартенситное превращение при нагружении (рис. 2, а). Позднее у подвижного захвата, где остановился фронт I прямого превращения, зарождается вторая полоса обратного превращения. Подвижные фронты обеих полос I и II движутся навстречу друг другу, но в момент времени $t_{3}=2100 \mathrm{~s}$ в месте зарождения полосы $A$ прямого мартенситного превращения (рис. $2, a, x_{A}=33 \mathrm{~mm}$ ) зарождается третья полоса обратного превращения. Ее фронты III и IV аннигилируют с фронтами I и II и обратное превращение завершается.

При скорости испытания $0.2 \mathrm{~mm} / \mathrm{min}$ связь мест зарождения полос обратного превращения с кинетикой прямого превращения тоже существует (рис. 3). Первая полоса обратного превращения зарождается у подвижного захвата, где остановился фронт IV полосы $B$ прямого превращения, а вторая - у подвижного захвата, где остановился фронт I полосы $A$. Однако аннигиляции фронтов обратного фазового превращения не произошло, а само превращение не завершилось.

Следует отметить, что при увеличении скорости испытания фронты обратного превращения становятся все более размытыми, степень локализации деформации на фронте падает, а при скорости $V_{\text {mach }}=0.8 \mathrm{~mm} / \mathrm{min}$ обратное превращение происходит делокализовано без формирования фронтов деформации.

\section{2. Фронты деформационно-индуцированного фазового превращения в trip-стали}

Термоупругое мартенситное превращение в исследуемой аустенитно-мартенситной стали может реализоваться на протяжении всего процесса деформирования от предела текучести и до разрушения. Будет ли при этом наблюдаться trip-эффект зависит от предшествующей термомеханической обработки [11-13]. На рис. 6 представлены деформационные кривые исследуемой стали для двух состояний (см. таблицу). Скорость нагружения $V_{\text {mach }}$ в обоих случаях составляла $0.4 \mathrm{~mm} / \mathrm{min}$. Необходимость такой относительно высокой скорости обусловлена тем, что пластичность стали больше $30 \%$, поэтому при испытании с меньшей скоростью время растяжения до разрушения превышает возможности аппаратуры для регистрации полей перемещений. В состоянии 1 материал демонстрирует п араболическую диаграмму нагружения без площадки текучести (рис. 6, кривая 1), $\sigma_{0.2}=285 \pm 28 \mathrm{MPa}$. Это согласуется с данными авторов [13], которые утверждают, что отжиг при $875 \mathrm{~K}$ нивелирует влияние trip-эффекта.

Когда напряжения достигают $\sim 1500 \mathrm{MPa}$, начинает проявляться прерывистая текучесть, которая продолжа-

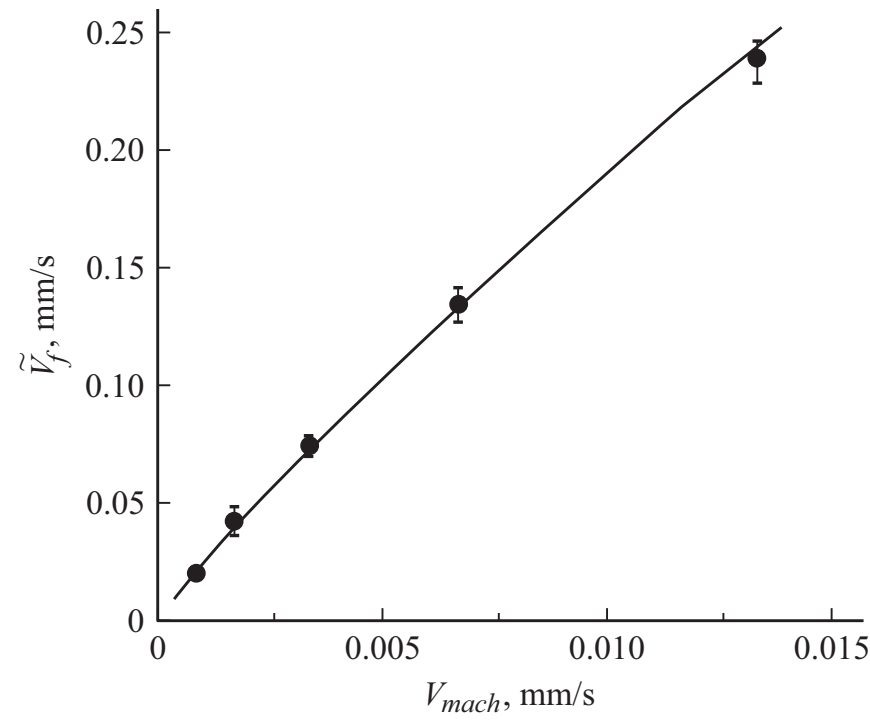

Рис. 5. Зависимость обобщенных скоростей фронтов от скорости нагружения в никелиде титана.

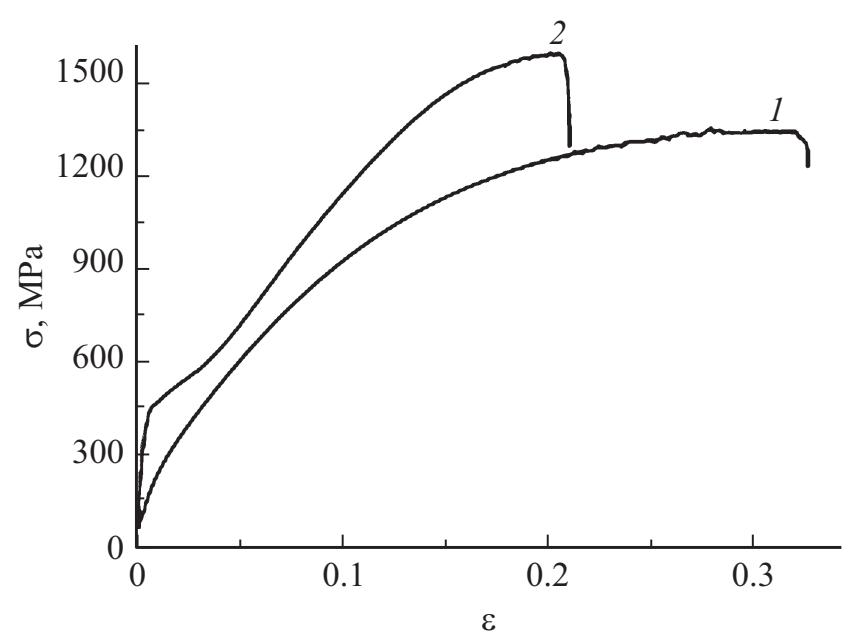

Рис. 6. Диаграммы нагружения trip-стали в состояниях 1 и 2.

ется вплоть до разрушения. В начале кривой нагружения деформация происходит макроскопически однородно по всей рабочей части образца. Однако, начиная с момента времени $t_{1}=1335 \mathrm{~s}$ (деформация $\varepsilon_{1}=0.23$ ), появляются подвижные фронты локализованной деформации, которые многократно проходят по рабочей части образца все оставшееся время до разрушения (рис. 7,a). После момента времени $t_{2}=1725 \mathrm{~s}\left(\varepsilon_{2}=0.29\right)$ зарождение и движение фронтов хорошо согласуется с появлением зубцов прерывистой текучести на диаграмме деформации. Поведение наблюдаемых фронтов аналогично поведению полос PLC в дуралюмине, где прерывистая текучесть также возникает на стадии параболического упрочнения и продолжается до разрушения [10].

В образцах после обжатия на $40 \%$ (состояние 2 ) на деформационной кривой (рис. 6, кривая 2) в интервале общих деформаций $\varepsilon_{t o t}=0.006-0.035$ появились 



Рис. 7. Хронограммы движения фронтов фазового превращения в состоянии 1 (a) и в состоянии 2 (b); стрелками указаны направления движения фронтов.

небольшой зуб и участок, на котором коэффициент упрочнения монотонно возрастает. При $\varepsilon_{t o t}=0.06$ коэффициент упрочнения достигает максимального значения и начинает снижаться, наступает стадия развитого параболического упрочнения с наложенной на нее прерывистой текучестью. Локализация деформации проявляется сразу после достижения зуба текучести $\sigma_{\mathrm{T}}=580 \mathrm{MPa}$. Во время деформирования на участке с возрастающим коэффициентом упрочнения в образце формируются четыре полосы локализованной деформации, подвижные фронты которых аннигилируют при встрече, тем самым разбивая рабочее поле образца на обособленные части (рис. $7, b)$. Этот процесс заканчивается к моменту времени $t_{g}=165 \mathrm{~s}\left(\varepsilon_{g}=0.035\right)$. Подобная ситуация описана выше для случая деформирования никелида титана при $V_{\text {mach }}=0.4 \mathrm{~mm} / \mathrm{min}$, а также наблюдалась ранее при множественном зарождении LB в малоуглеродистой стали $[9,10]$.

С началом стадии параболического упрочнения формируются полосы PLC, которые зарождаются и распространяются в пределах образованных ранее обособленных частей образца. Фронты этих полос движутся таким образом, что проходят весь образец по нескольку раз. Этот процесс продолжается вплоть до разрушения при $\sigma_{B}=1740 \mathrm{MPa}$ в момент времени $1240 \mathrm{~s}$ (рис. 6, кривая 2 и рис. $7, b)$. Важно отметить, что движение полос PLC происходит в границах обособленных зон образца только до момента времени $t_{s}=770 \mathrm{~s}$, когда на диаграмме нагружения становятся заметными зубцы прерывистой текучести (рис. 7, $b$ ).

\section{3. Автоволновая природа фронтов деформационно-индуцированного фазового превращения}

Результаты исследования кинетики фронтов деформационно-индуцированного фазового превращения и в никелиде титана и в trip-стали наводят на мысль о том, что их поведение может быть удовлетворительно описано в рамках автоволновой модели пластичности [6]. В общем случае автоволновые представления применимы к активным средам, содержащим распределенные по объему источники потенциальной энергии, которые в ходе внешнего воздействия возникают, релаксируют и вызывают изменения деформационной структуры самого объекта, т. е. представляют собой активные элементы среды [14]. В триггерных (бистабильных) активных средах, элементы которых имеют два состояния: метастабильное и стабильное, возникают автоволны переключения [14]. Применительно к деформационно-индуцированным фазовым превращениям - это упруго напряженная метастабильная фаза и релаксированная стабильная. В нашем случае, подобно тому, как это было в LB, существует граница между областью деформируемого объекта, где материал упруго напряжен и находится в аустенитном состоянии, и областью, где он релаксировал и перешел в мартенситное состояние. Этой границей является фронт полосы превращения в никелиде титана как при прямом, так и при обратном превращении. Фронты при движении заметают всю рабочую область и при встрече аннигилируют. Такое поведение соответствует автоволне переключения. Скорости фронтов определя- 
ются не только свойствами материала, но параметрами внешнего воздействия, т.е. скоростью нагружения, что тоже характерно для автоволн [14]. В зонах аннигиляции автоволн переключения существенно изменяются структура и состояние материала так, что они становятся источниками автоволн переключения при разгрузке в никелиде титана или разбивают объект на части, где деформационные процессы развиваются относительно независимо, как это происходит в trip-стали.

B trip-стали помимо фронтов LB возможно движение фронтов полос PLC, которые тоже представляют собой фронты деформационно-индуцированного превращения. Однако в отличие от фронтов LB фронты полос PLC многократно проходят по рабочей части объекта. Такое поведение характерно для автоволн возбуждения, которые возникают в активных средах с элементами, имеющими три состояния: покоя, возбуждения и рефрактерности [14]. В момент спада напряжения автоволна проходит по всему образцу (рис. 7, $a$ ) или в обособленной части образца (рис. $7, b)$ и превращение самоблокируется, элементы активной среды приходят в состояние рефрактерности [14]. Для того чтобы элементы среды вновь перешли в возбужденное состояние и прошла следующая автоволна возбуждения, напряжения должны возрасти. На рис. 8 можно видеть, что источниками автоволн возбуждения являются области зарождения первичных LB (автоволн переключения), а скорости их уменьшаются с ростом уровня деформирующих напряжений.

Для понимания природы установленного различия характера деформации никелида титана и trip-стали примем во внимание различие профилей фронтов для этих случаев. Из данных рис. 8 следует, что профиль фронта LB симметричен, а профиль фронтов полос PLC асимметричен, что может быть связано с разным характером релаксации напряжений на передней и задней образующих фронтов [15].

Положим далее, что развитие деформационной полосы есть термически активированный процесс, развивающийся со скоростью [16]

$$
V_{a w}=V_{0} \exp \left(-\frac{U-\gamma \sigma}{k_{B} T}\right) .
$$

В уравнении (3) $V$ ) const, $\gamma$ - активационный объем, $U$ - высота потенциального барьера, $T$ - температура, $k_{B}-$ постоянная Больцмана. На площадке текучести деформация протекает при напряжении, равном пределу текучести, т.е. $\sigma=\sigma_{\gamma}$. В отсутствие деформационного упрочнения можно полагать, что $\sigma_{\gamma} \approx-G b \sqrt{\Delta \rho}$, где $G$ - модуль сдвига, а $\Delta \rho=\Delta \rho(\varepsilon)=\rho_{m}-\rho_{0}$ - скачок плотности дефектов, ответственных за деформацию [7], на передней и задней образующих фронта деформационной полосы. Эти плотности могут быть определены экспериментально при анализе распределения микротвердости или радиуса кривизны деформированного кристалла вблизи остановившегося фронта Людерса и
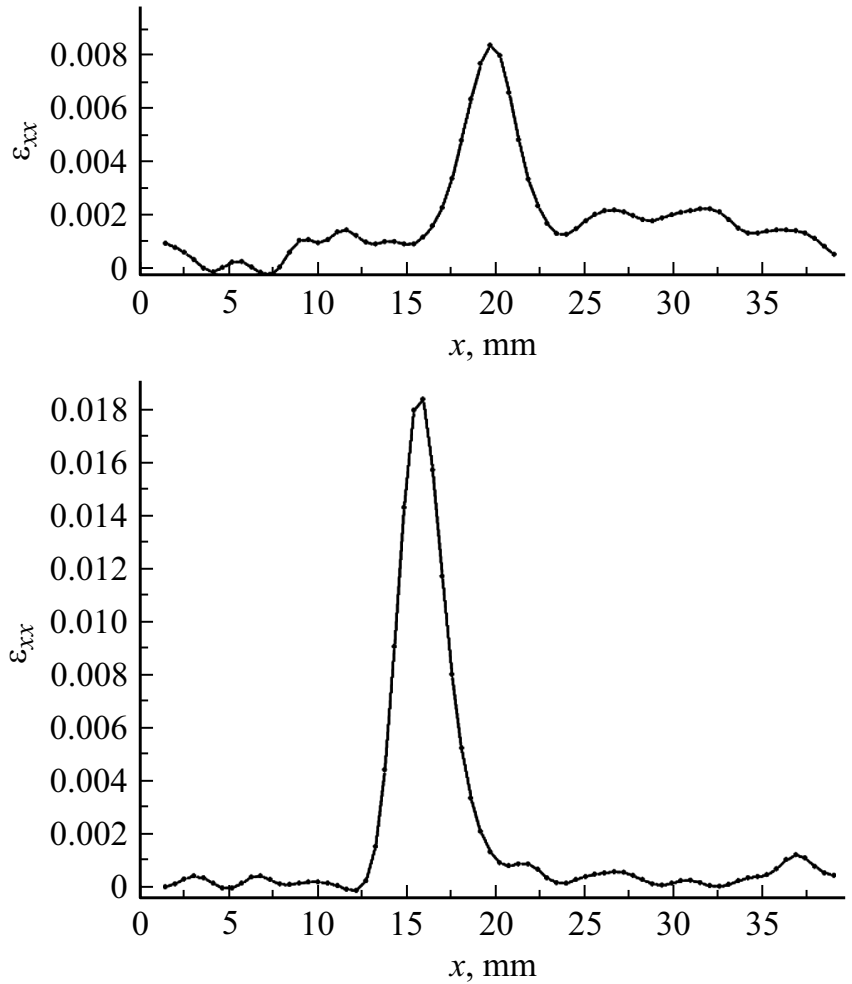

Рис. 8. Профили фронтов полосы Людерса $(a)$ и полосы Портевена-Ле Шателье $(b)$ в trip-стали.

модельного пересчета, как это предложено в работе [17]. Тогда

$$
V_{a w}=V_{0} \exp \left(-\frac{U+\gamma D b \sqrt{\Delta \rho}}{k_{B} T}\right) .
$$

Можно рассмотреть два случая соотношения плотностей дефектов на передней и задней образующих фронта [18].

i. Если $\rho_{m}-\rho_{0}=0$, то из уравнений (3) и (4) следует, что фронт деформации движется с постоянной скоростью $V_{a w} \sim \exp \sigma_{y} \sim \exp \sqrt{\Delta \rho}$. Это отвечает деформации на площадке текучести никелида титана, т. е. равномерному движению фронта Людерса.

ii. При $\rho_{m}-\rho_{0}<0$ из уравнения (4) следует, что

$$
V_{a w}=V_{0} \exp \left(-\frac{U+i \gamma D b \sqrt{|\Delta \rho|}}{k_{B} T}\right),
$$

где $i=\sqrt{-1}$. Уравнение (5) указывает на возможность возникновения колебательной динамики деформации при развитии PLC.

\section{Заключение}

Анализ результатов показывает, что деформационное фазовое превращение в сверхэластичном никелиде титана и в trip-стали может описываться как распространение полос Людерса и полос Портевена-Ле Шателье, 
поэтому к ним применима теория автоволновой локализованной пластичности [6]. На упругопластическом переходе деформируемые образцы обоих материалов представляют собой триггерные активные среды, элементы которых имеют два состояния: аустенитное и мартенситное. В процессе нагружения формируются полосы превращения, фронты которых представляют собой автоволны переключения локализованной пластичности. Количество полос превращения зависит от скорости движения захватов нагружающего устройства и возрастает с ростом последней. В момент зарождения каждая полоса имеет пару подвижных фронтов, т.е. является источником двух автоволн переключения. При встрече автоволны переключения аннигилируют, превращение прекращается. При разгрузке никелида титана формируются фронты обратного мартенситного превращения, которые также представляют собой автоволны переключения и подчиняются закономерностям, установленным для прямого превращения. Зоны зарождения и аннигиляции автоволн переключения прямого мартенситного превращения в никелиде титана при нагружении становятся источниками полос обратного превращения.

Нагружаемый образец trip-стали, где прямое деформационно-индуцированное мартенситное превращение на упругопластическом переходе не заканчивается, следует считать возбудимой активной средой. Здесь после прохождения и аннигиляции первичных автоволны локализованной пластичности, последующие повышение деформирующих напряжений снова приводит к активации зон зарождения. Они становятся источниками автоволн возбуждения локализованной пластичности, процессы зарождения и распространения которых многократно повторяются до тех пор, пока деформационно-индуцированное фазовое превращение аустенит $\rightarrow$ мартенсит не завершится полностью.

\section{Финансирование работы}

Работа выполнена в рамках Программы фундаментальных научных исследований государственных академий наук на 2013-2020 годы, направление III.23

\section{Конфликт интересов}

Авторы заявляют, что у них нет конфликта интересов.

\section{Список литературы}

[1] X.G. Wang, L. Wang, M.X. Huang. Acta Mater., 124, 17 (2017).

[2] M. Callahan, O. Hubert, F. Hild, A. Perlade, J.-H. Schmitt. Mater. Sci. Eng. A, 704, 391 (2017).

[3] X.G. Wang, C.H. Liu, B.B. He, C. Jiang, M.X. Huang. Mater. Sci. Eng. A, 761, 138050 (2019).

[4] С.А. Егоров, А.Е. Волков. ЖТФ, 87 (2), 204 (2017). [S.A. Egorov, A.E. Volkov. Tech. Phys., 62 (2), 230 (2017).]

[5] K. Kim, S. Daly. Smart Mater. Structure, 22, 075012 (2013).
[6] Л.Б. Зуев. Автоволновая пластичность. Локализация и коллективные моды (Физматлит, М., 2018) 207 с.

[7] В.С. Бойко, Р.И. Гарбер, А.М. Косевич. Обратимая пластичность кристаллов (Наука, М., 1991) 279 с.

[8] S. Avril, F. Pierron, M.A. Sutton, J. Yan. Mechan. Mater., 40, 729 (2008).

[9] V.I. Danilov, V.V. Gorbatenko, L.B. Zuev, D.V. Orlova. Mater. Sci. Eng. A, 714, 160 (2018).

[10] В.В. Горбатенко, В.И. Данилов, Л.Б. Зуев. ЖТФ, 87 (3), 372 (2017). [V.V. Gorbatenko, V.I. Danilov, L.B. Zuev. Tech. Phys., 62 (3), 395 (2017).]

[11] В.Ф. Терентьев, А.К. Слизов, Д.В. Просвирин. Деформация и разрушение материалов, 1, 14 (2016).

[12] А.Г. Пенкин, В.Ф. Терентьев, В.В. Рощупкин, А.К. Слизов, В.П. Сироткин. Деформация и разрушение материалов, 10, 35 (2016).

[13] В.Ф. Терентьев, Э.А. Елисеев, В.М. Матюнин, А.К. Слизов, А.Ю. Марченков, В.П. Сиротинкин, А.С. Баикин, Г.С. Севальнёв. Деформация и разрушение материалов, 11, 30 (2016).

[14] А.Ю. Лоскутов, А.С. Михайлов. Введение в синергетику (Наука, М., 1990) 270 с.

[15] В.3. Бенгус, Е.Д. Табачникова, В.Н. Островерх. ФТТ, 15 (11), 3452 (1973).

[16] D. Caillard, J.L. Martin. Thermally Activated Mechanisms in Crystal Plasticity (Elsevier, Oxford, 2003) 433 p.

[17] В.М. Андронов, А.М. Гвоздиков. ФММ, 63 (6), 1212 (1987).

[18] Л.Б. Зуев, С.А. Баранникова. Известия вузов. Физика, 62 (8), 28 (2019). [L.B. Zuev, S.A. Barannikova. Rus. Phys. J., $62(8), 1338$ (2019).] 